\title{
Isolation and Identification of a Microorganism which Produces Non Streptomyces Pepsin Inhibitor and N-Diazoacetyl-DL- norleucine Methylester Sensitive Acid Proteases ${ }^{\dagger}$
}

\author{
Sawao Murao, Kōhei Oda and Yoshiyuki Matsushita \\ Department of Agricultural Chemistry, College of Agriculture, \\ University of Osaka Prefecture, Sakai, Japan
}

Received November 22, 1972

\begin{abstract}
Non pepsin inhibitor (S-PI) and diazoacetyl-DL-norleucine methylester (DAN) sensitive acid proteases producing microorganism was isolated from farm soil of Osaka Prefecture.

The isolated strain was identified as Scytalidium lignicolum $\mathrm{M}-133$. When it was aerobically grown on a medium consisting of glucose $5 \%$, meat extract $1.5 \%$, yeast extract $0.1 \%$, $\mathrm{KH}_{2} \mathrm{PO}_{4} 0.2 \%, \mathrm{MgSO}_{4} \cdot 7 \mathrm{H}_{2} \mathrm{O} 0.05 \%$, at pH 3.5 and $25^{\circ} \mathrm{C}$, the strain produced two acid proteases, $\mathrm{A}$ and $\mathrm{B}$, in the culture broth.

The acid proteases $\mathbf{A}$ and $\mathbf{B}$ were not at all inactivated by S-PI and DAN. These acid proteases were expected to be a new type of acid protease from the viewpoint of the active site.
\end{abstract}

In our laboratory, pepsin inhibitor (S-PI) ${ }^{1,2)}$ was isolated from Streptomyces naniwaensis, which instantaneously formed an S-PI complex with pepsin (pepsin: $\mathrm{S}-\mathrm{PI}=1: 1$ ) and completely inactivated the caseinolytic activity of pepsin.

The S-PI completely inactivated the caseinolytic activities of the other acid proteases produced from Rhizopus chinensis, ${ }^{3)}$ Aspergillus saitoi, ${ }^{4)}$ Rhodotorula glutinis $\mathrm{K}-24,{ }^{5}$ Sacchromyces cerevisiae, ${ }^{6)}$ Trametes sanguinea, ${ }^{7 /}$ Mucor pusillus, ${ }^{8)}$ Cladosporium sp. No. $45-2^{91}$ and so on, as well as pepsin.

The active site of pepsin has been studied by many investigators ${ }^{10 \sim 12)}$ through the chemical modification with diazoketone compounds such as diazoacetyl-DL-norleucine methylester (DAN), and it was clarified that at the active site, there is a $\beta$-carboxyl group of an aspartic acid residue which reacts with the above reagents.

Sǒdek and Hofmann ${ }^{13,14}$ ) have isolated a peptide containing an active site residue from

$\uparrow$ Studies on New Acid Proteases from Scytalidium lignicolum M-133. Part I. See reference 18).

This study was presented at the Annual Meeting of the Agricultural Chemical Society of Japan at Sendai, April, 1972.
DAN-inactivated penicillopepsin (Penicillium janthinellum acid protease) and showed that the amino acid sequence of this peptide is quite similar to that of the active site of porcine pepsin. ${ }^{15}$ Takahashi and his colleagues $^{16,17)}$ studied the reaction of DAN with other microbial acid proteases from Rhizopus chinensis, Aspergillus saitoi and Mucor pusillus and with calf rennin, and assumed that the nature of the active site of acid protease was similar to each other over a very wide range of species, because these acid proteases were modified in the same manner as with pepsin.

Based on this, if there were a non S-PI and DAN sensitive acid protease, it would be expected to be a new acid protease which is different at the active site from the acid proteases reported up to date.

Therefore, as reported in the previous paper, ${ }^{18)}$ the authors tried to isolate a microorganism producing a non S-PI and DAN sensitive acid protease, and obtained a strain M-133 from soil. The strain was identified as Scytalidium lignicolum $\mathrm{M}-133$.

In the present paper, the isolation, identification, and cultural conditions of Scytalidium lignicolum $\mathrm{M}-133$ are described. 


\section{MATERIALS AND METHODS}

1. Preparation of $S-P I$ and $D A N$. Pepsin inhibitor (S-PI) was prepared as reported previously. ${ }^{21}$ Diazoacetyl-DL-norleucine methylester (DAN) was synthesized according to the method described by Rajagopalan, Stein and Moore. ${ }^{11}$

2. Assay of protease activity. Protease activity was assayed by the modified Anson method as reported previously. ${ }^{51}$

3. Screening of non $S-P I$ and DAN sensitive acid protease-producing microorganism. The screening of non S-PI and DAN sensitive acid protease-producing microorganism was carried out as follows. For the first screening, casein plate which contained $10 \mu \mathrm{g}$ $\mathrm{S}-\mathrm{PI} / \mathrm{ml}$ of the medium of Table I was used. Before

Table I. Media Composition for Screening

Medium I (for the first screening)

\begin{tabular}{|c|c|c|c|}
\hline Milk casein & $1 \%$ & Polypepton & $0.5 \%$ \\
\hline Glucose & $3 \%$ & Meat extract & $0.5 \%$ \\
\hline Yeast extract & $0.1 \%$ & Glucose & $1 \%$ \\
\hline $\mathrm{KH}_{2} \mathrm{PO}_{4}$ & $0.5 \%$ & Agar & $2 \%$ \\
\hline Agar & $2 \%$ & & \\
\hline \multicolumn{2}{|c|}{$\mathrm{pH} 3.0$ and 6.0} & \multicolumn{2}{|c|}{$\mathrm{pH} 3.0$ and 6.0} \\
\hline \multicolumn{2}{|c|}{ Arginine- $\mathrm{HCl}$} & 0.1 & $\%$ \\
\hline \multicolumn{2}{|l|}{ Glycerol } & 1.25 & $\%$ \\
\hline \multicolumn{2}{|l|}{$\mathrm{NaCl}$} & 0.1 & $\%$ \\
\hline \multicolumn{2}{|l|}{$\mathrm{K}_{2} \mathrm{HPO}_{4}$} & 0.1 & $\%$ \\
\hline \multicolumn{2}{|c|}{$\mathrm{MgSO}_{4} \cdot 7 \mathrm{H}_{2} \mathrm{O}$} & 0.05 & $\%$ \\
\hline \multicolumn{2}{|c|}{$\mathrm{FeSO}_{4} \cdot 7 \mathrm{H}_{2} \mathrm{O}$} & 0.001 & $\%$ \\
\hline \multicolumn{2}{|c|}{$\mathrm{ZnSO}_{4} \cdot 7 \mathrm{H}_{2} \mathrm{O}$} & \multicolumn{2}{|c|}{$0.0001 \%$} \\
\hline \multicolumn{2}{|c|}{$\mathrm{CuSO}_{4} \cdot 5 \mathrm{H}_{2} \mathrm{O}$} & \multicolumn{2}{|c|}{$0.0001 \%$} \\
\hline \multicolumn{2}{|c|}{$\mathrm{MnSO}_{4} \cdot n \mathrm{H}_{2} \mathrm{O}$} & \multicolumn{2}{|c|}{$0.0001 \%$} \\
\hline \multicolumn{2}{|l|}{ Agar } & 2 & $\%$ \\
\hline
\end{tabular}

pH 3.0 and 6.0

Medium II (for the secondary screening)

\begin{tabular}{ll}
\hline Polypeptone & $2 \%$ \\
Glucose & $3 \%$ \\
$\mathrm{KH}_{2} \mathrm{PO}_{4}$ & $0.1 \%$ \\
Yeast extract & $0.1 \%$ \\
\hline \multicolumn{1}{c}{$\mathrm{pH} \mathrm{3.5}$} & \\
\hline & \\
\hline Polypeptone & $0.5 \%$ \\
Meat extract & $0.5 \%$ \\
Glucose & $1 \%$ \\
Agar & $2 \%$ \\
\hline
\end{tabular}

pH 3.0 and 6.0 using, the possibility of isolating non S-PI sensitive acid protease-producing strain using S-PI casein plate was checked. That is, a cup containing $0.3 \mathrm{ml}$ of pepsin $(80 \mathrm{PU} / \mathrm{ml})$, which was usually employed for the assay of penicillin, was put on the S-PI casein plate and incubated at $37^{\circ} \mathrm{C}$ for $18 \mathrm{hr}$. The caseinolytic activity of pepsin was inactivated completely and no caseinolytic ring was observed at the margin of the cup. On the casein plate without S-PI, a caseinolytic ring was observed. If the acid protease is non S-PI sensitive, it must show the caseinolytic ring on the S-PI plate.

Using the S-PI casein plate, streak culture was carried out in the ordinary method. As the screening source, many kinds of soil, fruit and fish were used. After $3 \sim 6$ days culture at $25^{\circ} \mathrm{C}$, the colony having a caseinolytic ring at the margin was isolated. A second screening was performed using the isolated strains obtained, as mentioned above. The isolated strains were aerobically grown in medium II (Table I) at $25^{\circ} \mathrm{C}$. Employing the supernatant of culture broth, the inhibitory activity of S-PI and DAN was assayed.

4. Assay of inhibitory activity of $S-P I$. A half $\mathrm{ml}$ of the supernatant of culture broth was incubated with $0.5 \mathrm{ml}$ of $\mathrm{S}-\mathrm{PI}$ solution at $37^{\circ} \mathrm{C}$ for $10 \mathrm{~min}$ and the residual activity was assayed.

5. Assay of inhibitory activity of $D A N$. The inhibition reaction was carried out at $15^{\circ} \mathrm{C}$ with DAN according to the method of Lundblad. ${ }^{12}$

6. Identification of the strain $M-133$. In order to compare the morphological properties, the following type cultures were used.

(1) Scytalidium lignicolum CBS 233-57

(2) Scytalidium aurantiacum CBS 374-65

(3) Scytalidium album CBS 372-65

Color was estimated by reference to the "Guide to color standard."'19!

\section{RESULTS AND DISCUSSION}

1. Isolation of non-S-PI and DAN sensitive acid protease producing microorganism

For the screening of non S-PI and DAN sensitive acid protease-producing microorganism, various methods such as described above were employed.

In the first screening, many fungi, five fungi imperfecti-like strains and some yeast-like strains were obtained, but most of these acid proteases were completely inactivated by $100 \mu \mathrm{g} \mathrm{S}-\mathrm{PI}$.

The authors isolated $\mathrm{M}-133$ strain as the 
sole non S-PI sensitive acid protease producing microorganism from farm soil collected in Osaka Prefecture University.

The acid protease of culture filtrate was not inactivated even by $100 \mu \mathrm{g}$ of S-PI and was also not inactivated by DAN in the presence of cupric ions.

\section{Taxonomical investigation of the isolated strain $M-133$}

Taxonomical characteristics are summarized in Table II, and the photomicrographs are shown in Fig. 1, respectively.

Table II. Taxonomical Characteristics of Scytalidium lignicolum $\mathrm{M}-133$

1. Morphological characteristics

Conidia (arthrospore): Hyaline, oblong with truncate ends, $3.5 \sim 6.5 \mu \times 1.0 \sim 3.0 \mu$, produced by septation of apical part of hyphae and short branches arising at right angle.

Chlamydospores: Brownish black, spherical to elliptical, in chains, $5.0 \sim 12.0 \mu \times 4.5 \sim 7.5 \mu$.

Hyphae: Septate, hyaline, sometimes brownish, $1.2 \sim 3.5 \mu$ in width.

The organ for sexsual reproduction: None.

2. Cultural characteristics on various media.

Malt extract agar: Growth abundant, flocculent, light brownish gray, reverse dark yellowish brown, soluble pigment none.

Potato dextrose agar: Growth good, funicular, light gray, reverse radical dark olive gray, soluble pigment none.

Czapek's agar: Growth moderate, thin woolly, light gray, reverse dark yellow brown, soluble pigment none.

3. Physiological characteristics

Temperature: Growing well at $25^{\circ} \mathrm{C}$ to $30^{\circ} \mathrm{C}$, best at $30^{\circ} \mathrm{C}$, growth also occurred at $37^{\circ} \mathrm{C}$.

$\mathrm{pH}$ : Growing well at $\mathrm{pH} 4.5$ to $\mathrm{pH} 5.0$, best at pH 5.0.

The isolated strain $\mathrm{M}-133$ was concluded to be a species of Scytalidium, which belongs to a group of arthrospore-forming imperfect fungi, because it produced two kinds of spores (arthrospore and chlamydospore) under the same conditions.

In the genus Scytalidium, S. lignicolum, ${ }^{201}$ $S$. aurantiacum ${ }^{21)}$ and $S$. album ${ }^{21)}$ are known.

The morphological and physiological charac-

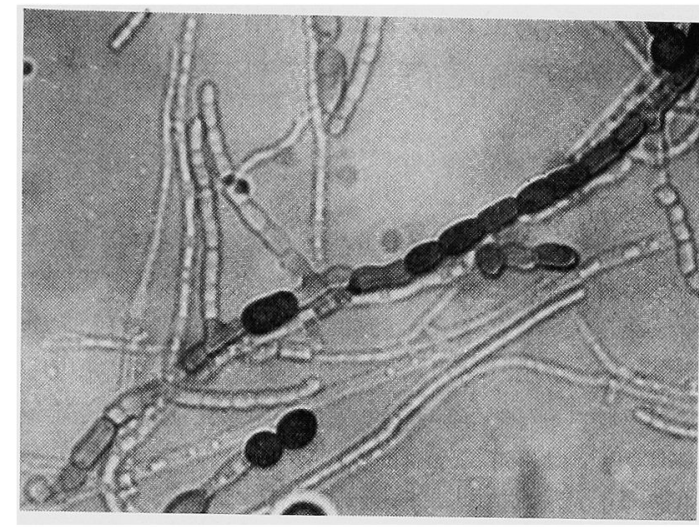

FIG. 1. Photomicrograph of Scytalidium lignicolum M-133.

Cells were cultured on potato dextrose agar for 9 days at $25^{\circ} \mathrm{C}$.

teristics of $\mathrm{M}-133$ were compared with their descriptions. In addition, type cultures obtained from Centraalbureau voor Shimmelcultures, The Netherlands (CBS) were cultured in parallel with $\mathrm{M}-133$.

According to the description, S. lignicolum has an optimum temperature for growth at $29^{\circ} \mathrm{C}$ and grows even at $36^{\circ} \mathrm{C}$, whereas the other two species have a good growth at $25^{\circ} \mathrm{C}$ but can not grow at $36^{\circ} \mathrm{C}$. On malt extract agar, the mycelium of $S$. aurantiacum was yellow red and $S$. album produced pale yellow pigment into the medium, but these characteristics were not observed in the type culture of $S$. lignicolum.

When the type culture was cultured on malt extract agar, the growth of $S$. lignicolum was good, whereas those of the other strains were poor and the chlamydospore formation was slow. The diagnostic characteristics of type cultures were compared with those of the M-133 strain.

The $\mathrm{M}-133$ strain had an optimum temperature for growth at $30^{\circ} \mathrm{C}$, even grew at $37^{\circ} \mathrm{C}$, the growth of the colony was good, and there was not the characteristic pigmentation at the mycelium and into the medium.

From these results, it was found that most of the morphological and physiological characteristics of $\mathrm{M}-133$ resemble those of S. lignicolum. 
Therefore, the authors identified the M-133 strain as Scytalidium lignicolum.

\section{Culture conditions for acid protease for- mation}

Among the carbon sources employed, glucose or mannose was best for acid protease production. Fructose and sucrose were suitable, but maltose, dextrin, glycerol were not.

The effect of several organic and inorganic nitrogen sources on acid protease production was also examined. Meat extract was the most suitable nitrogen source for acid protease production.

In addition, the effect of salts, vitamins, initial $\mathrm{pH}$, culture temperature and so on was tested.

The interesting fact was that the initial $\mathrm{pH}$ was a very important factor for acid protease production, as previously reported. ${ }^{22,23)}$ (Table III). The acidic $\mathrm{pH}(\mathrm{pH} 2.0 \sim 3.5)$ was suitable for acid protease production. When cultured at $\mathrm{pH} 4.5$, moderate growth was observed, but acid protease production was very scant. The maximal formation of acid protease was observed when the medium in Table IV was used under the following conditions: (Tem-

Table III. Effect of Initial pH on the Production of Acid Protease

The Scytalidium lignicolum M-133 was aerobically grown at $25^{\circ} \mathrm{C}$ for 5 days in the medium shown in Table IV.

\begin{tabular}{cccc}
\hline $\begin{array}{c}\text { Initial } \\
\mathrm{pH}\end{array}$ & $\begin{array}{c}\text { Protease } \\
\text { activity } \\
(\mathrm{PU} / \mathrm{ml})\end{array}$ & $\begin{array}{c}\text { Growth } \\
\text { (mg dry weight/ } \\
\text { ml broth) }\end{array}$ & Final pH \\
\hline 2.0 & 47 & 32 & 1.9 \\
2.8 & 59 & 33 & 2.2 \\
3.5 & 50 & 34 & 2.2 \\
4.5 & 12 & 23 & 5.5 \\
6.0 & 3 & 9 & 5.5 \\
\hline
\end{tabular}

Table IV. Composition of Culture Medium

\begin{tabular}{ll}
\hline Glucose & $5 \%$ \\
Meat extract & $1.5 \%$ \\
$\mathrm{KH}_{2} \mathrm{PO}_{4}$ & $0.2 \%$ \\
$\mathrm{MgSO}_{4} \cdot 7 \mathrm{H}_{2} \mathrm{O}$ & $0.05 \%$ \\
Yeast extract & $0.1 \%$ \\
\hline
\end{tabular}

pH 3.5 perature; $25^{\circ} \mathrm{C}$, aeration; 14 liter $/ \mathrm{min}$, agitation; $350 \mathrm{rpm}, 15$ liter of medium per 20 liter volume fermentor).

Seed culture was previously prepared by cultivating with $100 \mathrm{ml}$ of the same medium described above, in a $500 \mathrm{ml}$ volume shake flask at $25^{\circ} \mathrm{C}$ for $2 \sim 3$ days, and inoculum size was $2 \%(\mathrm{v} / \mathrm{v})$.

Figure 2 illustrates the time course of acid protease formation. The proteolytic activity in the supernatant of culture medium was highest at around $80 \mathrm{hr}$ cultivation, and the $\mathrm{pH}$ was gradually lowered from initial $\mathrm{pH}$ 3.5 to 2.0 .

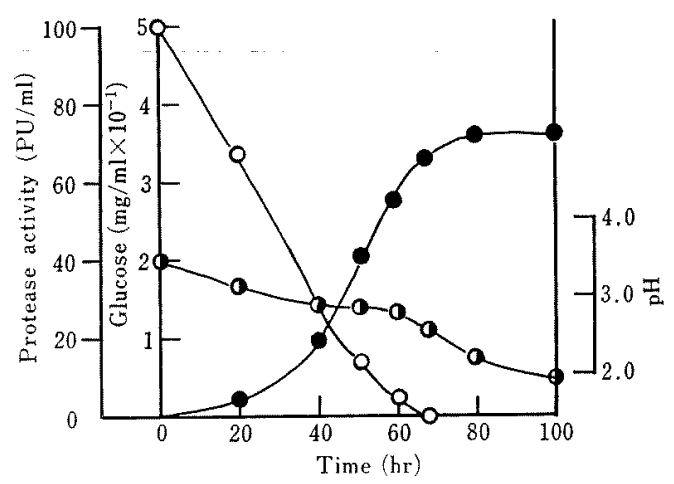

FIG. 2. Time Course of Acid Protease Production in Glucose-Meat Extract Medium.

The Scytalidium lignicolum M-133 was aerobically grown at $25^{\circ} \mathrm{C}$ in the medium indicated at Table IV. - , Protease activity $(\mathrm{PU} / \mathrm{ml}) ; 0-0, \mathrm{pH} ; \mathrm{O}-\mathrm{O}$, Glucose $(\mathrm{mg} / \mathrm{ml})$.

Compared with other acid protease-producing microorganisms, such as Rhodotorula glutinis $\mathrm{K}-24$ and Cladosporium sp. No. 45-2, the proteolytic activity was very low.

\section{Preliminary test for purification}

The supernatant of culture medium was concentrated to one tenth of its original volume in vacuo at $40^{\circ} \mathrm{C}$. The concentrated solution was dialyzed against $\mathrm{m} / 100$ acetate buffer ( $\mathrm{pH} 4.8$ ). The dialyzed solution was loaded on a DEAE-cellulose column, which was equilibrated with the same buffer described above, and eluted with linear gradient of $\mathrm{NaCl}$. As reported previously, ${ }^{18)}$ the authors 
found that Scytalidium lignicolum M-133 produced two acid proteases, A and B. The inhibition of the protease activity by S-PI and DAN was tested using crude acid proteases. Both enzymes were not inactivated by S-PI $(1,000 \mu \mathrm{g})$ and DAN, respectively.

In the next paper, the purification of $A$ and $B$ acid proteases and its general properties will be reported.

\section{REFERENCES}

1) S. Murao and S. Satoi, Agr. Biol. Chem., 35, 1477 (1971).

2) S. Satoi and S. Murao, ibid., 35, 1482 (1971).

3) J. Fukumoto, D. Tsuru and T. Yamamoto, ibid, 31, 710 (1967).

4) F. Yoshida and M. Nagasawa, Bull. Agr. Chem. Soc. Japan, 20, 257 (1956).

5) M. Kamada, K. Oda and S. Murao, Agr. Biol. Chem., 36, 1095 (1972).

6) T. Hata, R. Hayashi and E. Doi, ibid., 31, 150 (1967).

7) K. Tomoda and H. Shimazono, ibid., 28, 770 (1964).

8) J. Yu, S. Iwasaki, G. Tamura and K. Arima, ibid, 32, 1051 (1968).

9) S. Murao, S. Funakoshi and K. Oda, ibid., 36,
1327 (1972).

10) B. F. Erlanger, S. M. Vratsanos, N. Wassermann and A. G. Gooper, J. Biol. Chem., PC 3447 (1965); Biochem. Biophys. Res. Commun., 28, 203 (1967).

11) T. G. Rajagopalan, W. H. Stein and S. Moore, J. Biol. Chem., 241, 4295 (1966).

12) R. L. Lundblad and W. H. Stein, ibid., 244, 154 (1969).

13) J. Sŏdek and T. Hofmann, J. Biol. Chem., 243, 450 (1968).

14) idem, Can. J. Biochem., 48, 1014 (1970).

15) R. S. Bayliss, J. R. Knowles and G. B. Wybrandt, Biochem. J., 113, 377 (1969).

16) K. Takahashi, F. Mizobe and E. Ando, Seikagaku, 43, 444 (1971).

17) K. Takahashi, F. Mizobe and W. J. Chang, J. Biochem., 71, 161 (1972).

18) S. Murao, K. Oda and Y. Matsushita, Agr. Biol. Chem., 36, 1647 (1972).

19) "Guide to Colour Standard," Nippon Shikisai Kenkyusho, Japan.

20) A. Pesante, Ann. Sper. Agr. n.s. 11, 249 (1956),

21) A. Klingstron and L. Beyer, Svensk. Botanisk. Tidskrift, BD 59, H. 1 (1965).

22) S. Murao, M. Kamada, T. Nakaze, S. Ogura and K. Oda, Nippon Nôgeikagaku Kaishi, 46, 167 (1972).

23) M. Kamada, S. Ogura, K. Oda and S. Murao, ibid., 46, 171 (1972). 